\title{
Papers
}

\section{Environmental tobacco smoke and risk of respiratory cancer and chronic obstructive pulmonary disease in former smokers and never smokers in the EPIC prospective study}

\author{
P Vineis, L Airoldi, F Veglia, L Olgiati, R Pastorelli, H Autrup, A Dunning, S Garte, E Gormally, P Hainaut, C \\ Malaveille, G Matullo, M Peluso, K Overvad, A Tjonneland, F Clavel-Chapelon, H Boeing, V Krogh, D Palli, S Panico, \\ R Tumino, B Bueno-De-Mesquita, P Peeters, G Berglund, G Hallmans, R Saracci, E Riboli
}

\begin{abstract}
Objectives To investigate the association between environmental tobacco smoke, plasma cotinine concentration, and respiratory cancer or death.

Design Nested case-control study within the European prospective investigation into cancer and nutrition (EPIC). Participants 303020 people from the EPIC cohort (total 500 000) who had never smoked or who had stopped smoking for at least 10 years, 123479 of whom provided information on exposure to environmental tobacco smoke. Cases were people who developed respiratory cancers or died from respiratory conditions. Controls were matched for sex, age (plus or minus 5 years), smoking status, country of recruitment, and time elapsed since recruitment.

Main outcome measures Newly diagnosed cancer of lung, pharynx, and larynx; deaths from chronic obstructive pulmonary disease or emphysema. Plasma cotinine concentration was measured in 1574 people.

Results Over seven years of follow up, 97 people had newly diagnosed lung cancer, 20 had upper respiratory cancers (pharynx, larynx), and 14 died from chronic obstructive pulmonary disease or emphysema. In the whole cohort exposure to environmental tobacco smoke was associated with increased risks (hazard ratio 1.30, 95\% confidence interval 0.87 to 1.95 , for all respiratory diseases; $1.34,0.85$ to 2.13 , for lung cancer alone). Higher results were found in the nested case-control study (odds ratio $1.70,1.02$ to 2.82, for respiratory diseases; $1.76,0.96$ to 3.23 , for lung cancer alone). Odds ratios were consistently higher in former smokers than in those who had never smoked; the association was limited to exposure related to work. Cotinine concentration was clearly associated with self reported exposure (3.30, 2.07 to 5.23, for detectable/non-detectable cotinine), but it was not associated with the risk of respiratory diseases or lung cancer. Frequent exposure to environmental tobacco smoke during childhood was associated with lung cancer in adulthood (hazard ratio 3.63, 1.19 to 11.11 , for daily exposure for many hours).

Conclusions This large prospective study, in which the smoking status was supported by cotinine measurements, confirms that environmental tobacco smoke is a risk factor for lung cancer and other respiratory diseases, particularly in ex-smokers.
\end{abstract}

\section{Introduction}

Environmental tobacco smoke, or involuntary smoking, comprises sidestream smoke from the smouldering tobacco between puffs and exhaled mainstream smoke from the smoker. More than 50 investigations, mostly case-control studies, have shown that involuntary smoking is associated with an increased risk for lung cancer. ${ }^{2}$ In 2002, a working group of the International Agency for Research on Cancer evaluated the epidemiological evidence and included environmental tobacco smoke in group I (human carcinogen). ${ }^{3}$ Few cohort studies are available, however, with accurate information on potential confounders or effect modifiers. We analysed data from the large European prospective investigation into cancer and nutrition (EPIC) to assess the relation between environmental tobacco smoke and lung cancer, upper respiratory cancers, and death from chronic obstructive pulmonary disease (COPD) or emphysema, limiting our analysis to never smokers and people who had not smoked for more than 10 years. The advantage of the cohort design is the lack of recall bias as information about exposure was collected before onset of disease.

\section{Methods}

The EPIC cohort

EPIC is a multicentre study, coordinated by the International Agency for Research on Cancer (Lyons), in which more than 500000 healthy volunteers were recruited in 10 European countries (Sweden, Denmark, Norway, the Netherlands, United Kingdom, France, Germany, Spain, Italy, Greece). ${ }^{5}$ The cohort includes men and women, mostly in the age range 35-74 at recruitment. Recruitment took place between 1993 and 1998. Diet was measured by questionnaires specific for each country, designed to address local dietary habits and to provide high compliance. Six countries administered a dietary questionnaire, which provided data on up to 350 food items per country. In France, Spain, and Ragusa (Italy) similar dietary questionnaires but structured by meals were used. The centres in Spain and Ragusa performed a face-to-face dietary interview with a computerised dietary programme, the others used a self administered questionnaire. All dietary measurement instruments have been validated previously in a series of studies within the various source populations participating in EPIC.

Lifestyle questionnaires included questions on reproductive history, use of oral contraceptives and hormone replacement 
therapy, education, physical activity, history of previous illness or surgical operations, and history of consumption of tobacco and alcoholic beverages. Eleven centres (in France, Italy, Denmark, Sweden, the Netherlands, and Potsdam, Germany) collected data on exposure to environmental tobacco smoke, by asking about any exposure, place of exposure, and exposure during childhood. This resulted in a subgroup of 123479 (only never smokers or former smokers who had stopped for at least 10 years), most of whom had information on any exposure and place of exposure.

The follow up was based on data from population cancer registries in seven of the participating countries: Denmark, Italy, the Netherlands, Norway, Spain, Sweden, and the United Kingdom. In France, Germany, and Greece we used a combination of methods including health insurance records, cancer and pathology registries, and active follow up through study participants and their next of kin. Mortality data were also obtained from the cancer registries or mortality registries at the regional or national level. Follow up was virtually 100\% complete. We used ICD-10 (international classification of diseases, 10th revision). The median follow up time was seven years.

\section{Design of the nested case-control study (GenAir)}

The nested case-control study (GenAir) studied the relation between air pollution or environmental tobacco smoke and newly diagnosed cancers of the bladder, lung, oral cavity, pharynx, or larynx, or leukaemia. The study also identified and included deaths from respiratory diseases (chronic obstructive pulmonary disease and emphysema). We included only people who had never smoked or who had stopped smoking for at least 10 years.

We matched three controls per case for assessment of exposure and the analysis of questionnaire data and two controls per case for laboratory analyses. Matching was introduced to allow strict control of potentially confounding variables because other risk factors may be stronger than environmental tobacco smoke. In addition, matching was needed for laboratory analyses, to avoid differential sample degradation between cases and controls. Controls were matched for sex, age (plus or minus 5 years), smoking status (never/former smoker), country of recruitment, and time elapsed since recruitment (months). To identify controls we randomly sampled the study base (whole cohort at inception $(\mathrm{n}=500000))$ on the basis of the characteristics of each case until we found three subjects who matched; 66 cases were matched to 198 controls, while 40 cases were matched to two controls only (total 80 controls), and eight to one control (total 286 controls) (for 17 we were unable to find a control to match).

\section{Laboratory analyses}

Cotinine was extracted from plasma by ion exchange chromatography and analysed by liquid chromatographyatmospheric pressure ionization-tandem mass spectrometry (API LC-MS/MS) at the Mario Negri Institute (Milan) in 1574 participants, irrespective of the information available on environmental tobacco smoke. These were all the cases included in GenAir and their matched controls (2:1) for whom serum and DNA samples were available.

Polymorphisms in genes involved in carcinogenesis were analysed by Taqman in white blood cells. We developed a score for the number of "at risk polymorphisms" in the genes GSTM1, GSTM3, GSTPi, GSTT1, GYP1A1, NAT2, MnSOD, MPO, NQO1, and CYP1B1. "At risk polymorphisms" are gene variants with impaired function. ${ }^{6}$

\section{Statistical analyses}

We analysed the whole cohort with Cox's proportional hazards models, using age at diagnosis (cases) or at last contact as the dependent variable, as suggested by Korn et al. ${ }^{7}$ Hazard ratios were adjusted by sex, smoking habit (former or never smoker), country, education in four levels, energy intake, consumption of fruit and vegetables, and physical activity. Energy, dietary items, and physical activity were used as continuous variables or in quarters (models using quarters gave virtually identical results and are not shown). In the nested case-control study we computed odds ratios and 95\% confidence intervals in conditional logistic regression models ${ }^{8}$ that included educational level, energy intake, fruit and vegetables consumption, and physical activity as further adjustment variables in addition to matching variables. Matched pairs were inherently matched by batch. We also performed unconditional logistic regression analyses, which were based on the whole set of controls and gave results virtually identical to those based on conditional analysis (when not otherwise specified). We assessed interaction by creating indicator variables for the combination of single variables (for example, environmental tobacco smoke and country) and by the Breslow-Day test for heterogeneity. ${ }^{8}$ Analyses were performed with the SAS package (Cary, NC, USA) for a personal computer.

\section{Results}

Information on exposure to environmental tobacco smoke was collected from 123 479/303 020 (40.8\%) participants who had never smoked or former smokers in the EPIC cohort. Of these 97 people developed lung cancer, 20 developed upper respiratory cancers (pharynx, larynx), and 14 died from chronic obstructive pulmonary disease or emphysema during the seven years of follow up. Table 1 shows details for cases, controls, and the whole cohort.

Plasma cotinine was measured in 1574 GenAir subjects (with or without information on environmental tobacco smoke). The method was highly specific and sensitive with a detection limit of $0.05 \mathrm{ng}$ of cotinine per $\mathrm{ml}$ of plasma in $50 \mu \mathrm{l}$ samples. We excluded 47 participants with values $>10 \mathrm{ng} / \mathrm{ml}$ because they were likely to be active smokers $(n=41)$ or sniffers/chewers $(\mathrm{n}=6)$. Of the 1527 remaining subjects, $461 \quad(30 \%)$ had detectable concentrations of plasma cotinine with an overall mean value of $0.92 \mathrm{ng} / \mathrm{ml}(\mathrm{SD} 0.96 \mathrm{ng} / \mathrm{ml})$. Table 2 shows the mean cotinine concentrations in the 374 people with information on environmental tobacco smoke. Cotinine concentrations were clearly associated with self reported exposure to environmental tobacco smoke (odds ratio $3.30,95 \%$ confidence interval 2.07 to 5.23 , for detectable/non-detectable cotinine, $\mathrm{P}<0.0001)$. We did not reassess environmental tobacco smoke after cotinine measurements-that is, these are two independent sources of information.

Table 3 shows results for the whole cohort (Cox's proportional hazards model) and for the nested case-control study (conditional regression models). Increased odds ratios and hazard ratios were associated with environmental tobacco smoke exposure at recruitment for all respiratory diseases and for lung cancer alone in the whole cohort and in the nested study. Higher odds ratios were observed separately in each country (data not shown; test for heterogeneity, $\mathrm{P}=0.08$ ). The differences observed in risks associated with environmental tobacco smoke between sexes were not significant (test for heterogenity $\mathrm{P}=0.66$ ).

Former smokers had higher risks for respiratory disease (attaining significance) than those who had never smoked in 
Table 1 Distribution of cases and controls by relevant variables

\begin{tabular}{|c|c|c|c|c|c|}
\hline & Lung cancer ( $n=97)$ & Upper respiratory cancer $(n=20)$ & COPD deaths $(n=14)$ & Controls $(n=286)$ & Whole cohort $(n=123479)$ \\
\hline Men & 27 & 15 & 7 & 105 & 27532 \\
\hline Women & 70 & 5 & 7 & 181 & 95947 \\
\hline Mean (SD) age (years) & $58.0(7.5)$ & $59.4(6.4)$ & $59.1(7.2)$ & $57.9(7.6)$ & $53.2(8.3)$ \\
\hline \multicolumn{6}{|l|}{ School level attained: } \\
\hline None or primary & 34 & 10 & 7 & 75 & 27819 \\
\hline Secondary/technical & 39 & 6 & 4 & 141 & 52975 \\
\hline University degree & 23 & 3 & 3 & 66 & 32782 \\
\hline Missing values & 1 & 1 & - & 4 & 9903 \\
\hline \multicolumn{6}{|l|}{ Smoking: } \\
\hline Former smokers & 38 & 7 & 8 & 113 & 20556 \\
\hline Never smokers & 59 & 13 & 6 & 173 & 102923 \\
\hline \multicolumn{6}{|l|}{ ETS exposure: } \\
\hline Home and/or work: & & & & & . \\
\hline Yes & 57 & 11 & 10 & 153 & 71722 \\
\hline No & 40 & 9 & 4 & 133 & 51757 \\
\hline \multicolumn{6}{|l|}{ Home: } \\
\hline Yes & 20 & 4 & 5 & 56 & 23396 \\
\hline No & 49 & 9 & 6 & 136 & 58675 \\
\hline Missing ${ }^{*}$ & 28 & 7 & 3 & 94 & 41408 \\
\hline \multicolumn{6}{|l|}{ Work: } \\
\hline Yes & 49 & 10 & 9 & 123 & 58653 \\
\hline No & 22 & 3 & 2 & 72 & 28620 \\
\hline Missing ${ }^{*}$ & 26 & 7 & 3 & 91 & 36206 \\
\hline
\end{tabular}

${ }^{\star}$ For these subjects we investigated home and work exposures combined.

both the whole cohort and the case-control analyses. The raised risks in both analyses, were limited to exposures related to work, with significant risk estimates around 1.5 to 2.0. Cotinine was not associated with lung cancer or other diseases. The odds ratio for detectable versus undetectable cotinine concentrations and respiratory disease/cancer was 0.9 (0.5 to 1.8 ).

Table 4 shows the distribution of self reported exposure to environmental tobacco smoke during childhood in those who had never smoked, in the centres where information was

Table 2 Cotinine measurements in 374 people* with information on exposure to environmental tobacco smoke

\section{Cotinine}

\begin{tabular}{lccc} 
& \multicolumn{3}{c}{ Cotinine } \\
\cline { 2 - 4 } ETS status & Mean (SD)† & $\begin{array}{c}\text { Detectable }(>\mathbf{0 . 0 5} \\
\mathbf{n g} / \mathbf{m l})\end{array}$ & Undetectable \\
\hline Yes $(\mathrm{n}=189)$ & $0.55(0.96)$ & 89 & 100 \\
\hline No $(\mathrm{n}=174)$ & $0.17(0.49)$ & 37 & 137
\end{tabular}

*Eleven people with cotinine concentration $>10 \mathrm{ng} / \mathrm{ml}$ excluded. $\dagger \mathrm{P}<0.0001$ for difference (Wilcoxon Rank sum test). collected $(n=60182)$. Increased risks were present for the categories "daily" and "daily, many hours," with significant confidence intervals for the latter.

We analysed the role of environmental tobacco smoke in lung cancer according to the score of "at risk" alleles for polymorphisms in metabolic genes. The odds ratio associated among carriers of at least three of the at risk polymorphisms was $2.86(0.79$ to 10.35$)$, while for those with one or two alleles it was 1.33 (0.82 to 2.18). This difference was detected in unconditional analysis because numbers were too small for conditional analysis.

\section{Discussion}

\section{Environmental tobacco smoke and risk of cancer}

We followed up the EPIC cohort for a median of seven years and identified incident cases of lung cancer and upper respiratory cancer and deaths from respiratory conditions among former smokers and those who had never smoked. We found that respi-

Table 3 Environmental tobacco smoke (ETS) exposure (home and/or work) and respiratory disease (including deaths from lung cancer, larynx or pharynx cancer, and deaths from chronic obstructive pulmonary disease) or lung cancer alone, in whole cohort ( $\mathrm{n}=123479,131$ cases) and in nested case-control study ( $\mathrm{n}=114$ cases, 286 controls)

Hazard ratios $(95 \% \mathrm{Cl})$

Odds ratios* $(95 \% \mathrm{Cl})$

\begin{tabular}{|c|c|c|c|c|}
\hline & & & & \multirow[b]{2}{*}{ Lung cancer } \\
\hline \multicolumn{2}{|c|}{\begin{tabular}{ll}
\cline { 2 - 3 } & Respiratory disease \\
\end{tabular}} & Lung cancer & Respiratory disease & \\
\hline \multicolumn{5}{|c|}{ Exposure to ETS at home and/or at work (yes/no): } \\
\hline Model I $†$ & 1.21 (0.82 to 1.78$)$ & $1.25(0.80$ to 1.96$)$ & 1.64 (0.99 to 2.69) & $1.75(0.96$ to 3.18$)$ \\
\hline \multicolumn{5}{|l|}{ Model II‡: } \\
\hline All & 1.30 (0.87 to 1.95$)$ & 1.34 (0.85 to 2.13$)$ & 1.70 (1.02 to 2.82) & $1.76(0.96$ to 3.23$)$ \\
\hline Former smokers & $2.32(1.07$ to 5.01$)$ & 2.32 (0.94 to 5.71$)$ & 3.11 (1.06 to 9.18$)$ & NA \\
\hline Never smokers & 1.02 (0.63 to 1.66$)$ & $1.05(0.60$ to 1.82$)$ & 1.45 (0.75 to 2.80$)$ & $1.42(0.63$ to 3.20$)$ \\
\hline Men & 1.72 (0.81 to 3.66$)$ & $1.96(0.68$ to 5.67$)$ & 1.79 (0.63 to 5.09$)$ & NA \\
\hline Women & 1.15 (0.71 to 1.86$)$ & 1.20 (0.71 to 2.02$)$ & 1.46 (0.76 to 2.80$)$ & NA \\
\hline ETS only at home & $1.11(0.71$ to 1.74$)$ & $1.03(0.60$ to 1.76$)$ & 1.10 (0.60 to 2.02) & 0.82 (0.37 to 1.82$)$ \\
\hline ETS only at work & 1.55 (1.03 to 2.32$)$ & 1.65 (1.04 to 2.63 ) & 2.05 (1.22 to 3.47$)$ & 2.17 (1.16 to 4.08$)$ \\
\hline
\end{tabular}

${ }^{*}$ Computed by conditional logistic regression analysis.

$\dagger$ Adjusted by sex, age (plus or minus 5 years), smoking (former or never smoker), country, and school years.

$\ddagger$ Additionally adjusted by energy intake, fruit and vegetables consumption, and physical activity. 
Table 4 Cox's proportional hazards model for relation between exposure to environmental tobacco smoke in childhood and risk of lung cancer in whole cohort in 60182 people who have never smoked

\begin{tabular}{lccc}
$\begin{array}{l}\text { Exposure to ETS in } \\
\text { infancy }\end{array}$ & Whole cohort & No of cases & HR $^{*}$ (95\% CI) \\
\hline Never (reference) & 29164 & 15 & 1.0 \\
\hline Seldom & 12376 & 8 & $1.08(0.45$ to 2.59$)$ \\
\hline Few times/week & 8360 & 7 & $1.45(0.59$ to 3.61) \\
\hline Daily & 8063 & 8 & $2.04(0.85$ to 4.94$)$ \\
\hline Daily, many hours & 2219 & 4 & 3.63 (1.19 to 11.11) \\
\hline
\end{tabular}

${ }^{*}$ Adjusted for sex, country, education, vegetables, fruit, total energy, physical activity. P value for trend 0.018

ratory conditions and lung cancer alone were associated with self reported environmental tobacco smoke exposure at the time of recruitment. The association was consistently observed after we stratified by country. The association was stronger in the nested case-control study than in the whole cohort. This observation has two possible explanations: chance or better adjustment for confounders through careful matching. The association, however, was limited to exposures related to work, possibly because of higher levels of exposure.

\section{Advantages and limits of the study design}

Our study design had several advantages: its prospective nature-that is, the fact that exposure was investigated years before the onset of disease (so that recall bias can be excluded); accurate ascertainment of disease through cancer registries and clinical records, with histological confirmation whenever available; the relatively large number of cases accrued among former smokers and never smokers; and the availability of blood samples that allowed validation of questionnaire information by cotinine measurement.

One limitation, however, was the lack of detailed information on environmental tobacco smoke exposure (with scanty data, for example, on the number of hours of exposure) and the fact that information was collected only once. Concerning the quality of information on environmental tobacco smoke, it is, however, unlikely that people who reported that they were former smokers were actually current smokers as we excluded those with cotinine concentrations $>10 \mathrm{ng} / \mathrm{ml}(\mathrm{n}=47)$.

\section{Former smokers}

Former smokers had higher risks for respiratory disease than those who had never smoked. Although the difference between former and never smokers might be due to chance $(\mathrm{P}=0.58$, test for heterogeneity), the observation suggests that former smokers might be more susceptible to the effects of environmental tobacco smoke. Three centres collected information on duration of smoking and number of cigarettes smoked for former smokers. In these centres the odds ratio for respiratory diseases and environmental tobacco smoke exposure, adjusted for all variables indicated above, plus duration and number of cigarettes smoked, was 1.5 ( 0.5 to 4.5 ), based on 24 cases, identical to the unadjusted estimate $(1.5,0.5$ to 4.6$)$. Therefore, the fact that the association with lung cancer is stronger in former smokers is difficult to understand. While bias is unlikely, one possible explanation is that former smokers are more susceptible to low level exposure to environmental tobacco smoke because they already have mutations in their cells.

\section{Biomarkers}

The biological plausibility of a causal association between environmental tobacco smoke exposure and lung cancer is reinforced by the suggestion that having more then three polymor-

\section{Want is already known on this topic}

Environmental tobacco smoke has been recognised as a human carcinogen by a working group of the International Agency for Research on Cancer

\section{What this study adds}

In a large European prospective study (EPIC) exposure to environmental tobacco smoke was confirmed with plasma cotinine measurement

There was an increased risk in association with exposure to environmental tobacco smoke for respiratory diseases, specifically lung cancer

The risk was higher among former smokers (stopped for at least 10 years) than among never smokers, which could indicate the greater susceptibility of former smokers due to already existing mutations

The association was limited to exposure related to work, which was particularly important in European countries

phic genes increases the odds ratio to 2.86 instead of 1.76. This, if confirmed, would be an example of "mendelian randomisation. ${ }^{, 9}$ Previous studies have found that the association between environmental tobacco smoke and lung cancer was stronger in subjects with polymorphisms in GSTM $1,{ }^{10}{ }^{11}$ but one study had negative results, although statistical power was limited. ${ }^{12}$

Cotinine concentrations were not associated with the risk of lung cancer. This could be expected, as previous studies have stressed the limitations of cotinine as a biomarker of exposure. ${ }^{3}$ Cotinine is an expression of the past 24 hours of exposure and is valuable mainly to exclude current smoking rather than estimating long term exposure to environmental tobacco smoke. ${ }^{34}$ However, we found a non-significant association in those with three or more polymorphic alleles (data not shown).

\section{Childhood exposure}

Environmental tobacco smoke exposure during childhood showed an association with lung cancer, particularly among those who had never smoked; the association was significant for daily exposure for many hours. The observation is not new, but the literature is not entirely consistent. ${ }^{13}{ }^{14}$ To our knowledge, ours is the first prospective study to report such association. Of course, the reliability of information on exposure to environmental tobacco smoke in childhood can be questioned, although most people should be able to recall whether their parents smoked. The uptake of carcinogens in exposed children is widespread and quantitatively important. ${ }^{15}$

\section{Conclusions}

Our study contributes to the existing literature reinforcing the conclusions of the IARC Monograph Working Group ${ }^{34}$ that there is sufficient evidence on the carcinogenicity of environmental tobacco smoke in humans.

Mortality data for the Netherlands were obtained from Statistics Netherlands.

Contributors: The authors of this study were P Vineis and L Airoldi, L Olgiati, R Pastorelli (Institute of Pharmacological Research, Mario Negri, Milan, Italy); F Veglia, G Matullo (ISI Foundation, Turin, Italy); H Autrup (Department of Occupational and Environmental Medicine, Aarhus, Denmark); A Dunning (Department of Oncology, University of Cambridge); S Garte (Genetics Research Institute, Milan, Italy); E Gormally, P Hainaut, C Malaveille, R Saracci, E Riboli (International Agency for 
Research on Cancer, Lyons, France); M Peluso (Molecular Biology Laboratory, CSPO, Florence, Italy); K Overvad (Department of Clinical Epidemiology, Aalborg Hospital and Aarhus University Hospital, and Department of Epidemiology and Social Medicine, University of Aarhus, Denmark); A Tjonneland (Institute of Cancer Epidemiology, Danish Cancer Society, Copenhagen, Denmark); F Clavel-Chapelon (INSERM U521, Gustave Roussy Institute, Villejuif, France); H Boeing (German Institute of Human Nutrition, Potsdam-Rehbücke, Germany); V Krogh (Department of Epidemiology, National Cancer Institute, Milan, Italy); D Palli (Molecular and Nutritional Epidemiology Unit CSPO, Scientific Institute of Tuscany, Florence, Italy); S Panico (Department of Clinical and Experimental Medicine, Federico II University, Naples, Italy); R Tumino (Ragusa Cancer Registry, Azienda Ospedaliera "Civile MP Arezzo," Ragusa, Italy); B Bueno-DeMesquita (Centre for Nutrition and Health, National Institute for Public Health and the Environment, Bilthoven, Netherlands); P Peeters (Julius Centre for Health Sciences and Primary Care, University Medical Centre, Utrecht, Netherlands); G Berglund (Malmö Diet and Cancer Study, Lund University, Malmö, Sweden); and G Hallmans (Department of Nutritional Research, University of Umeå, Sweden). All authors directly participated in the planning, execution, or analysis of the study. Specific responsibilities were: conception and design-PV, ER, ER, RS; acquisition of data-KO, AT, FC-C, HB, VK, DP, SP, RT, BB-De-M, PP, GB, GH, PV; laboratory analyses, data analysis and interpretation of data-LA, FV, LO, RP, HA, AD, SG, EG, $\mathrm{PH}, \mathrm{CM}, \mathrm{GM}, \mathrm{MP}$. PV drafted the article and is guarantor.

Funding: European Community (5th Framework Programme) (grant QLK4-CT-1999-00927), Compagnia di San Paolo, Europe Against Cancer Programme of the European Commission (SANCO), Deutsche Krebshilfe, Deutsches Krebsforschungszentrum, German Federal Ministry of Education and Research, Danish Cancer Society, Health Research Fund (FIS) of the Spanish Ministry of Health, Spanish Regional Governments of Andalucia, Asturia, Basque Country, Murcia, and Navarra, Cancer Research UK, Medical Research Council, Stroke Association, British Heart Foundation, Department of Health, Food Standards Agency, Wellcome Trust, Greek Ministry of Health, Greek Ministry of Education, Italian Association for Research on Cancer (AIRC), Italian National Research Council, Dutch Ministry of Public Health, Welfare and Sports, World Cancer Research Fund, Swedish Cancer Society, Swedish Scientific Council, Regional Government of Skåne, Sweden, Norwegian Cancer Society, Research Council of Norway.

Competing interests: None declared.

Ethical approval: GenAir was approved by the ethical committee of the International Agency for Research on Cancer and by all the local ethical committees of the participating centres.
1 Hackshaw AK, Law MR, Wald NJ. The accumulated evidence on lung cancer and environmental tobacco smoke. BMJ 1997;315:980-8.

2 Vineis P, Alavanja M, Buffler P, Fontham E, Franceschi S, Gao YT, et al. Tobacco and cancer: recent epidemiological evidence. J Natl Cancer Inst 2004;96:99-106.

3 International Agency for Research on Cancer. IARC monographs on the evaluation of carcinogenic risks to humans. Vol 83. Lyons: International Agency for Research on Cancer (in press).

4 Benowitz NL. Biomarkers of environmental tobacco smoke exposure. Environ Health Perspect 1999;107(suppl 2): 349-55.

5 Riboli E, Hunt KJ, Slimani N, Ferrari P, Norat T, Fahey M, et al. European Prospective Investigation into Cancer and Nutrition (EPIC): study populations and data collection. Public Health Nutr 2002;5(6B):1113-24.

6 Vineis P, Malats N, Lang M, d'Errico A, Caporaso N, Cuzick J, Boffetta P. Metabolic polymorphisms and susceptibility to cancer. Lyons: International Agency for Research on Cancer, 1999. (IARC Sci Publ No 148.)

7 Korn EL, Graubard BI, Midthune D. Time-to-event analysis of longitudinal follow-up of a survey: choice of the time-scale. Am J Epidemiol 1997;145:72-80.

8 Breslow NE, Day NE. Statistical methods in cancer research. Vol I. The analysis of case-control studies. Lyons: International Agency for Research on Cancer, 1980. (IARC Sci Publ No 32.)

9 Davey Smith G, Ebrahim S. Mendelian randomization: prospects, potentials, and limitations. Int J Epidemiol 2004;33:30-42.

10 Kiyohara C, Wakai K, Mikami H, Sido K, Ando M, Ohno Y. Risk modification by CYP1A1 and GSTM1 polymorphisms in the association of environmental tobacco smoke and lung cancer: a case-control study in Japanese nonsmoking women. Int J Cancer 2003;107:139-44.

11 Bennett WP, Alavanja MC, Blomeke B, Vahakangas KH, Castren K, Welsh JA, et al. Environmental tobacco smoke, genetic susceptibility, and risk of lung cancer in neversmoking women. J Natl Cancer Inst 1999;91:2009-14.

12 Malats N, Camus-Radon AM, Nyberg F, Ahrens W, Constantinescu V, Mukeria A, et al. Lung cancer risk in nonsmokers and GSTM1 and GSTT1 genetic polymorphisms. Cancer Epidemiol Biomarkers Prev 2000;9:827-33.

13 Lee CH, Ko YC, Goggins W, Huang JJ, Huang MS, Kao EL, Wang HZ. Lifetime environmental exposure to tobacco smoke and primary lung cancer of non-smoking Taiwanese women. Int J Epidemiol 2000;29:224-31.

14 Tredaniel J, Boffetta P, Little J, Saracci R, Hirsch A. Exposure to passive smoking during pregnancy and childhood, and cancer risk: the epidemiological evidence. Paediatr Perinat Epidemiol 1994;8:233-55.

15 Hecht SS, Ye M, Carmella SG, Fredrickson A, Adgate JL, Greaves IA, et al. Metabolites of a tobacco-specific lung carcinogen in the urine of elementary school-aged children. Cancer Epidemiol Biomarkers Prev 2001;10:1109-16.

(Accepted 23 November 2004)

doi $10.1136 /$ bmj.38327.648472.82

Imperial College, London W2 1PG

$\mathrm{P}$ Vineis epidemiologist

See contributors section for details of other authors

Correspondence to: P Vineis p.vineis@imperial.ac.uk 